\title{
An Educational Tool for Browsing the Semantic Web
}

\author{
Sujin YOO, Younghwan KIM, Seongbin PARK* \\ Korea University \\ Anam-dong, Seongbuk-gu, Seoul, Korea \\ e-mail: \{mynameislydia, tsohr, hyperspace\}@korea.ac.kr
}

Received: January 2013

\begin{abstract}
The Semantic Web is an extension of the current Web where information is represented in a machine processable way. It is not separate from the current Web and one of the confusions that novice users might have is where the Semantic Web is. In fact, users can easily encounter RDF documents that are components of the Semantic Web while they navigate among Web pages. In addition, the number of RDF documents on the Web is ever-increasing and a lot of educational materials in RDF format become available on the Web. In this paper, we propose a simple Semantic Web browser by which non-expert users such as secondary school students who do not know technical details about the Semantic Web can browse through HTML documents and RDF documents.
\end{abstract}

Keywords: Semantic Web, Semantic Web browser.

\section{Introduction}

The Semantic Web is different from the current Web in that it contains information which is processable by machines (e.g., computers or computer programs; Antoniou and van Harmelen, 2004). Typically, the documents that exist on the Semantic Web are RDF (Resource Description Framework) documents and non-expert users who do not have technical backgrounds on the Semantic Web technologies may not understand what they mean. Since its inception, the number of RDF documents on the Web has been growing and these can be found using search engines such as Watson (d'Aquin and Motta, 2011). In addition, the number of educational resources has been also increasing and Linked Education which intends to utilize them for education has become important (Dietze et al., 2012).

Recently, Semantic Web browsers (Berners-Lee et al., 2006; Dzbor et al., 2003; Bizer and Gauß, 2007) that help users navigate among the documents on the Semantic Web has been proposed. To use these browsers, users can either set up the functionality using a Web browser such as Firefox (Berners-Lee et al., 2006; Dzbor et al., 2003) or access a server (Bizer and Gauß, 2007). With these browsers, users can see RDF documents that are normally lists of triples that consist of "subject, predicate, object". However, one

\footnotetext{
${ }^{*}$ Corresponding author.
} 
difficulty that non-expert users who know what the Semantic Web is, but do not have technical knowledge about the Semantic Web may have is that they cannot understand what the screenshot shows. In other words, a list of triple structures may be hard to understand. For example, Tabulator and Disco show table views and a user can move pages by choosing links in RDF files. But if the user does not know the triple structure of RDF documents, the user cannot understand the contents. What they need is a simpler browser that looks almost like a normal Web browser by which they can surf on the set of RDF documents and HTML documents freely.

In this paper, we present a simple Semantic Web browser for non-expert users without technical backgrounds about the Semantic Web. An advantage of our system is that users do not need to know technical details about the Semantic Web technologies. Instead, all they need to know are URIs for the documents they want to visit. For examples, teachers can create a hyperlinked educational environment that consists of RDF documents, HTML documents, and hyperlinks. Then, students who do not know anything about the Semantic Web can freely browse through the educational documents for learning. They can also see how the components of a document are interrelated because they are shown as interlinked nodes.

This paper is structured as follows. Section 2 describes related works. Section 3 explains the structure of the system. Section 4 describes feedbacks from persons who used the proposed system. Finally, Section 5 concludes the paper and describes ongoing research.

\section{Related Works}

The Semantic Web can be viewed as a universal library where a lot of resources can be accessed in various contexts by users (Marshall and Shipman, 2003). It is not separate from the current Web and one way to access the information on the Semantic Web is by navigation because it is a hypertext (Goble et al., 2001). However, since documents on the Semantic Web are not HTML documents, users need special systems called Semantic Web browsers to visit Semantic Web pages (Berners-Lee et al., 2006; Dzbor et al., 2003; Bizer and Gauß, 2007).

Tabulator can be set up as an extension of Firefox browser and users can browse through HTML documents and RDF documents on the Web. In addition, users can see the documents stored in their local machines. Figure 1 shows the screenshot of Tabulator. While this figure is well-organized and shows details about the RDF document, it may be difficult to understand if a user is not familiar with vocabularies used; i.e., isDefined, isIncluded, etc. In other words, although Tabulator is very convenient for users who know technical details about the Semantic Web such as the triple structure of an RDF file, etc., non-experts users may find the result difficult to understand.

Magpie can be also used in Firefox and it supports highlighting words that appear in web pages using ontologies that represent vocabularies and their relationships in a domain of interest (Staab and Studer, 2009). It can help understanding the contents of documents 


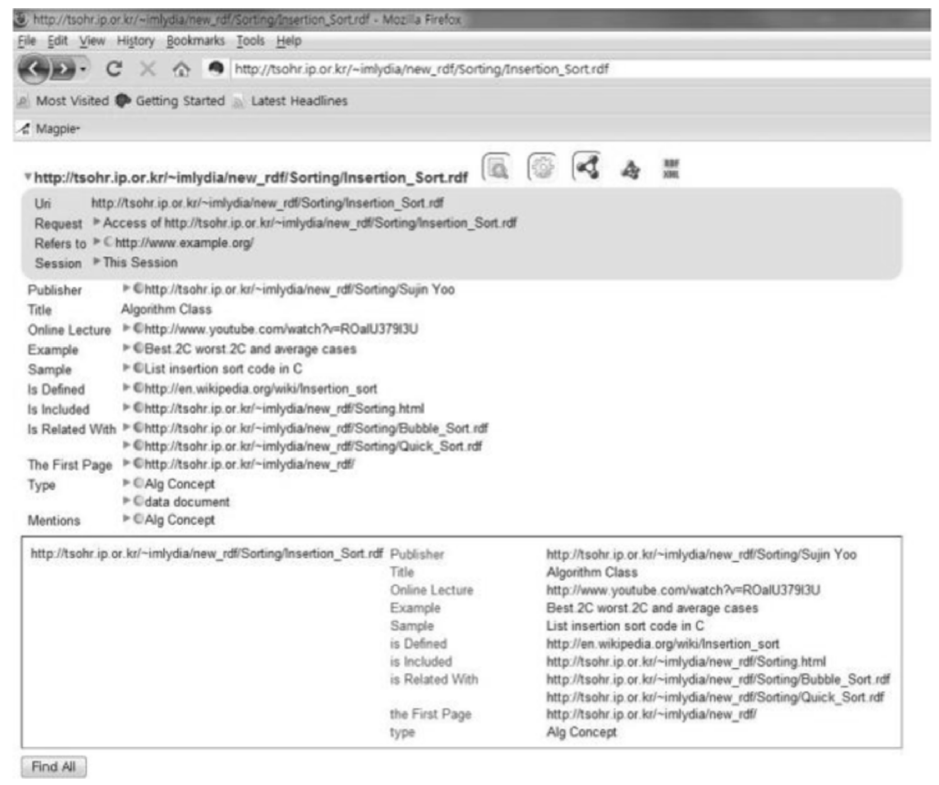

Fig. 1. Screenshot of Tabulator.

because words that are related to definitions in the ontologies can be easily identified. Magpie can also show local documents stored in local machines. However, it does not display RDF documents since it is not targeted for surfing the Semantic Web. In other words, although Magpie is a good example of a Semantic Web browser, the focus is on semantically browsing through documents and not rendering RDF documents.

Disco is a web service that shows the contents of RDF documents and some of HTML documents identified URIs. While it can show well-organized views like Tabulator, it does not show local documents stored in local machines. In addition, understanding the contents of the documents displayed can be difficult for novice users without technical background on the Semantic Web. Figure 2 shows the screenshot of Disco that displays the same document in Fig. 1.

\section{System Structure}

Our system is an extension of the system (Kim et al., 2012) which displays RDF documents using GraphViz ${ }^{2}$. When a user types an RDF URI (Uniform Resource Identifier) ${ }^{3}$, it translates the RDF document identified by the URI into an SVG (Scalable Vector Graphics $)^{4}$ document. The current version allows users to navigate among the set of RDF documents and HTML documents freely. It looks almost like a simple Web browser and

\footnotetext{
${ }^{2}$ http: / / www.graphviz.org/.

${ }^{3}$ http: //www.ietf.org/rfc/rfc3986.txt.

${ }^{4}$ http: //www.w3 .org/Graphics/SVG/.
} 


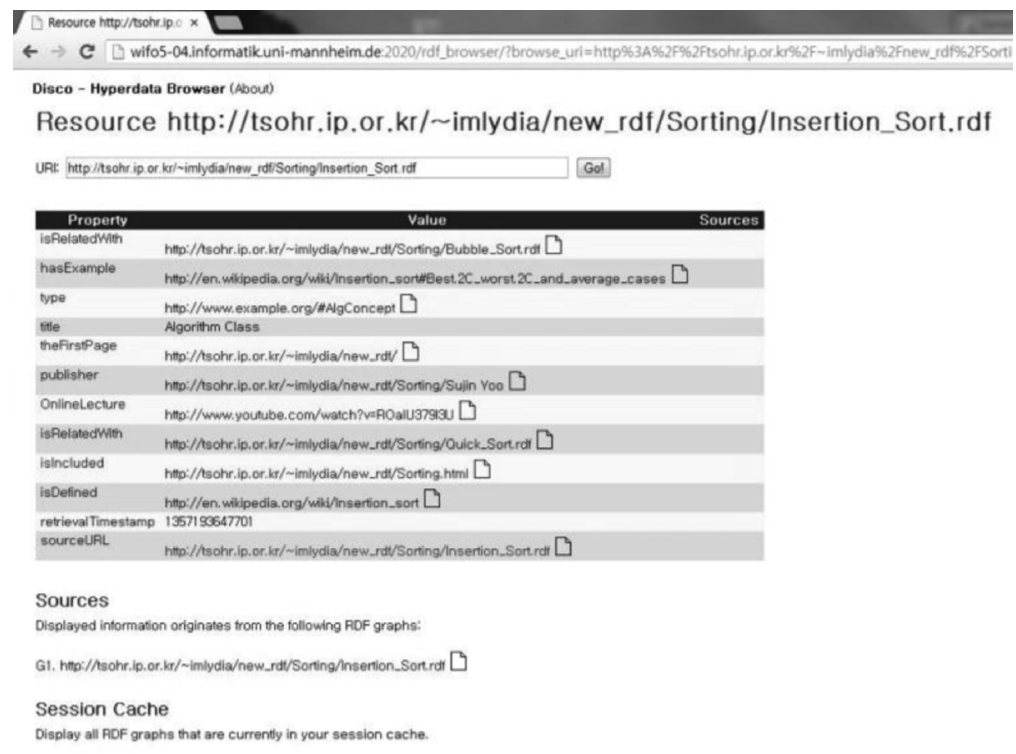

Fig. 2. Screenshot of Disco.

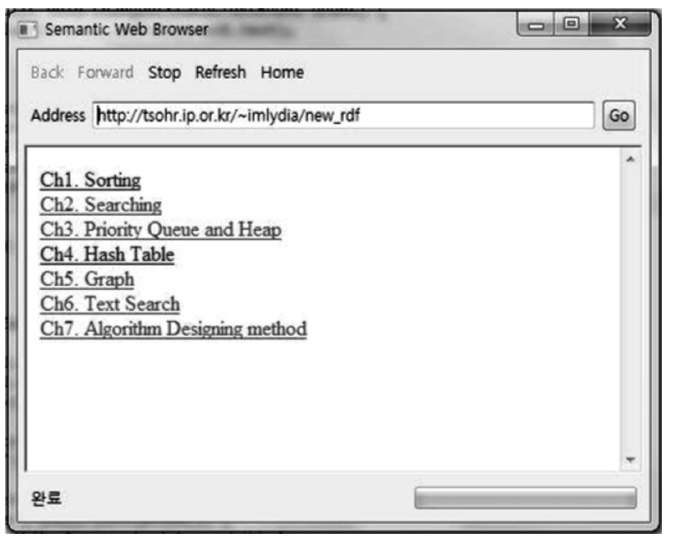

Fig. 3. Screenshot of the system that displays an HTML document.

displays RDF documents in an intuitive form and HTML documents as well. Figures 3 and 4 show screenshots of the proposed system, respectively. Note that Figure 4 shows the same RDF document used in Figs. 1 and 2 in the previous section.

Our system has been implemented in Java and we used packages such as SWT ${ }^{5}$, Jena ${ }^{6}$, Protege ${ }^{7}$. Figure 5 shows the structure of our system. The system consists of several components. When a user starts the system, it checks whether the document that the user

\footnotetext{
${ }^{5}$ http: //www.eclipse.org/swt/.

${ }^{6}$ http: //jena. apache.org/.

${ }^{7}$ http://protege.stanford.edu/.
} 


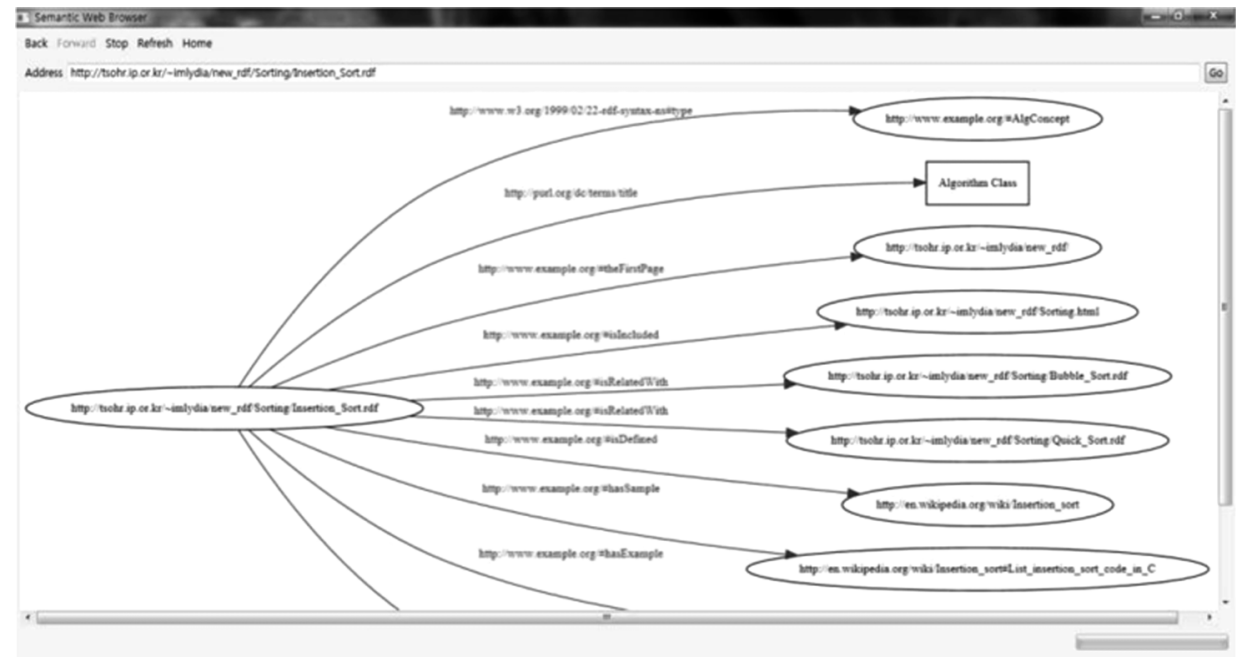

Fig. 4. Screenshot of the system that displays an RDF document.

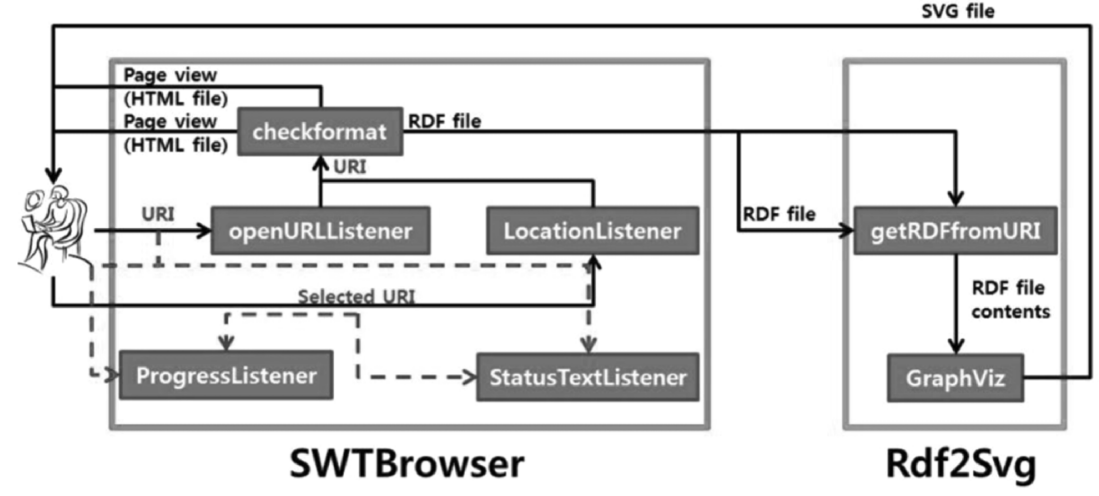

Fig. 5. The structure of the proposed system.

is visiting is an RDF document or not (checkformat). If it is an RDF document, then modules in Rdf2Svg (getRDFfromURI and GraphViz) convert it into an SVG file and the system displays the result. Otherwise, it just shows the document. Our system checks validity of an RDF document using RDF Validator ${ }^{8}$.

Figure 6 shows how our system is different from related works.

Our system supports navigating among HTML documents and RDF documents. It can show documents stored in local machines and provide an intuitive screenshot. A user can click hyperlinks which correspond to one of subjects, predicates, and objects. Tabulator and Disco do not support navigation by clicking predicates.

\footnotetext{
${ }^{8}$ http://www.w3.org/RDF/Validator/.
} 


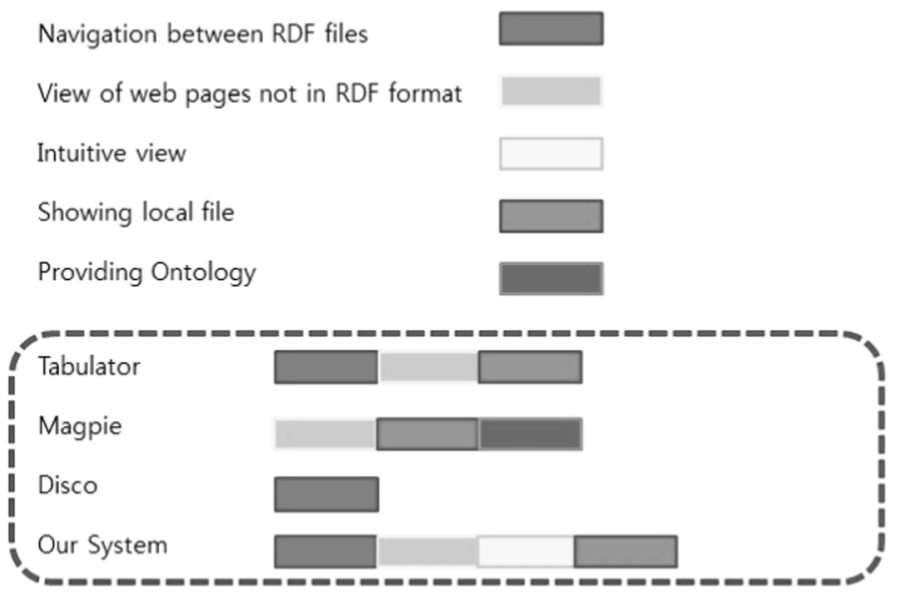

Fig. 6. Comparison of Semantic Web browsers.

\section{Evaluation}

As a simple demonstration about how easy our system is to use, we report feedbacks from two persons who used the system to surf the set of HTML documents and RDF documents. They have experiences in IT fields, but do not know technical details about the Semantic Web. Figure 7 shows the site structure for the experiment which consists of 23 RDF documents and 8 HTML documents.

One positive comment about the system is that it is easy to recognize the structure of the whole contents. In addition, it provides an intuitive view since the structure is drawn as a graph. That can help users understand the relationships of the parts of the documents. In the mean time, one desirable feature which does not exist in the current version is that the system expands in place so that part of the whole page is replaced instead of changing the whole document view. This will help users pay attention to both the whole structure and a local part of the structure. One negative comment about our system is that the current version only has two types of nodes which are shown as circles and rectangles. In a sense, that may be too simple to represent various parts of RDF documents.

One participant said that Tabulator showed simpler views than our system because it removed duplicated parts which appeared in our system. The other participant pointed out that our system merely transforms RDF documents into SVG files which could be displayed. That is true since our system does not provide extra functionalities other than showing the documents in both RDF and HTML formats correctly.

When asked whether the proposed system could help learning, both of them said positively because at least the system can be used by non-experts to browse through the set of RDF documents and HTML documents which can be designed by technical persons. All they need to do is follow carefully designed links such as Walden's path (Li et al., 2012). They also mentioned that it would be better if the current system could support other functions such as an efficient way of displaying the relationships of the nodes instead of showing all, which could become very complex. 


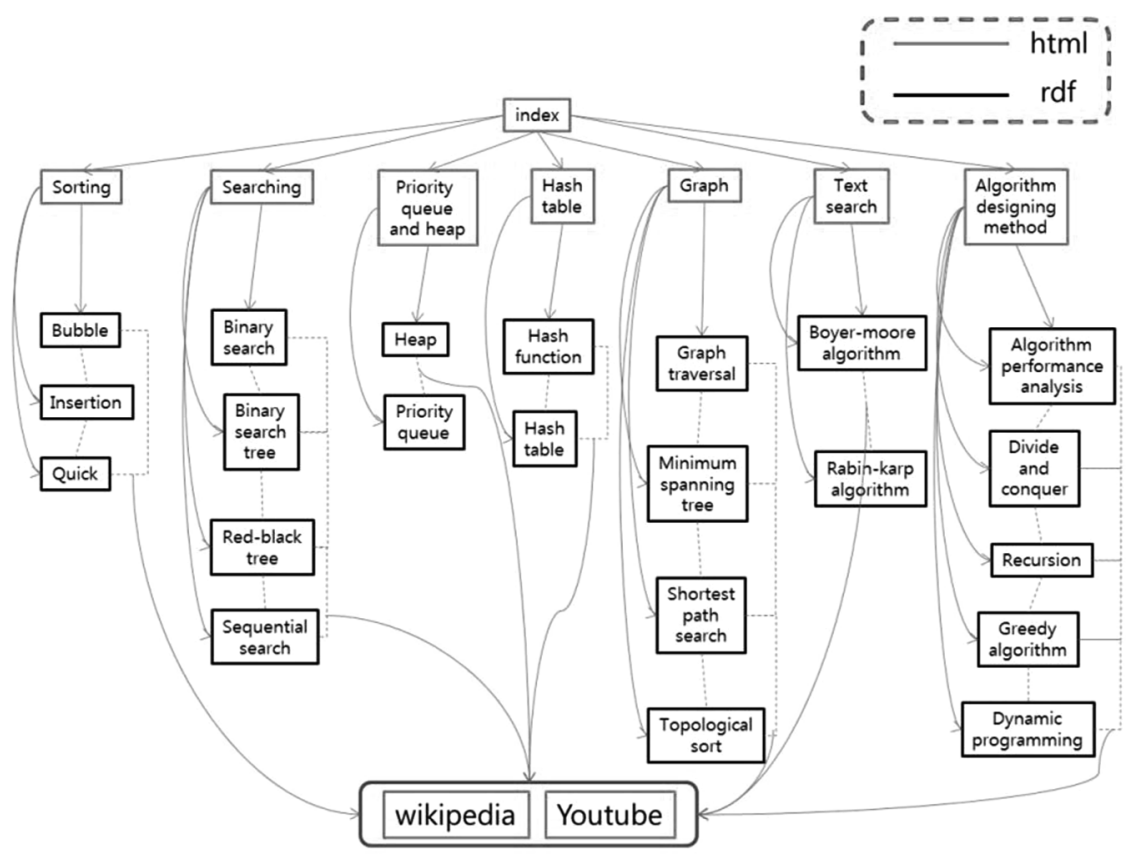

Fig. 7. Site structure.

Finally, they mentioned that experienced users who know the Semantic Web would find Tabulator convenient because it shows details about the documents in a wellorganized way.

\section{Conclusions}

The number of RDF documents on the Web is growing and many of them can be used for educational purposes. There are already a lot of educational resources in HTML format on the Web. Since the Semantic Web is not separate from the current Web and users can easily encounter RDF documents while surfing on the Web, it is important to have a simple browser by which users without technical backgrounds on the Semantic Web can browse through HTML documents and RDF documents.

In this paper, we proposed a simple Semantic Web browser that can help non-expert users navigate among the set of HTML documents and RDF documents. The target audience of our system is people who can visit both RDF documents and HTML documents freely without having any technical backgrounds on the Semantic Web. While well-known Semantic Web browsers such as Tabulator, Magpie, Disco, etc. can be used by experienced users, we believe that our system can be used by novice users for learning because it is almost like a Web browser that can be used immediately without learning how to use. Teachers can provide well-designed set of RDF documents and HTML documents which are hyperlinked. 
Currently, we are extending the proposed system so that it can support expand in place function as well as simplified views of documents rendered. We are also implementing simple inference functions by which automatic recognition of related documents are provided. In the future, we plan to use the proposed system in secondary schools for teaching science.

\section{References}

Antoniou, G., van Harmelen, F. (2004). A Semantic Web Primer, The MIT Press.

d'Aquin, M., Motta, E. (2011). Watson, more than a semantic Web search engine, Semantic Web, 2(1), 55-63. Berners-Lee, T., Chen, Y., Chilton, L. Connolly, D., Dhanaraj, R., Hollenbach, J., Lerer, A., Sheets, D. (2006). Tabulator: exploring and analyzing linked data on the semantic Web. In: Proceedings of the 3rd International Semantic Web User Interaction Workshop, Georgia, USA.

Bizer, C., Gauč, T. (2007). Disco - Hyperdata Browser. A Simple Browser for Navigating the Semantic Web. http: //wifo5-03.informatik. uni-mannheim.de/bizer/ng4j/disco/.

Dietze, S., Yu, H.Q., Giordano, D., Kaldoudi, E., Dovrolis, N., Taibi, D. (2012). Linked education: interlinking educational eesources and the Web of data. In: Proceedings of the 27th ACM Symposium on Applied Computing (SAC-2012), Special Track on Semantic Web and Applications, Trento, Italy.

Dzbor, M., Domingue, J., Motta, E. (2003). Magpie: towards a semantic Web browser. In: 2nd International Semantic Web Conference, Florida, USA.

Goble, C., Bechhofer, S., Carr, L., Roure, D.D., Hall, W. (2001). Conceptual open hypermedia = The semantic Web? In: Proceedings of the WWW2001, Semantic Web Workshop, Hongkong, China.

Kim, Y., Yoo, S., Park, S. (2012). A semantic Web browser for novice users. In: 6th International Conference on Complex, Intelligent and Software Intensive Systems, Palermo, Italy, 806-809.

Li, Y., Logasa Bogen II, P., Pogue, D., Furuta, R., Shipman, F. (2012). Collaborative authoring of Walden's paths. TPDL 2012, LNCS, 7489, Paphos, Cyprus, 461-467.

Marshall, C.C., Shipman, F.M. (2003). Which semantic Web. In: Proceedings of the 14th ACM Conference on Hypertext and Hypermedia, Nottingham, United Kingdom, 57-66.

Staab, S., Studer, R. (2009), Handbook on Ontologies, Springer Publishing Company.

S. Yoo is a doctoral student in Computer Science Education Department at Korea University, Seoul, Korea. Her research interests include Semantic Web, algorithm, linked data, adaptive hypermedia, and computer science education.

Y. Kim is a software developer in Romax Technology in Korea. He graduated from Korea University with bachelor's degree in computer science education. He worked in Castis, an IPTV company, from 2007 to 2010 as a database and application developer. He is interested in computer architecture, networks, software cost estimation, computer software and Semantic Web.

S. Park is a professor at the Computer Science Education Department of Korea University in Seoul, Korea. He graduated from the University of Southern California with doctoral degree in computer science. His research interests include Semantic Web, adaptive hypermedia, and computer science education. 


\section{Semantinio tinklo naršymo edukacinis ịrankis}

Sujin YOO, Younghwan KIM, Seongbin PARK

Semantinis tinklas - tai saityno plètinys, kuriame informacija vaizduojama kompiuteriui apdoroti tinkamu būdu. Tai nèra atskirta nuo esamo tinklo, ir semantinio tinklo konceptas neretai klaidingai suprantamas. Vartotojai, naršydami internete, gali susidurti su RDF dokumentais, kurie yra semantinio tinklo komponentai. RDF dokumentụ skaičius tinkle auga ir vis daugiau edukaciniu ištekliu tampa prieinamais RDF formatu. Straipsnyje siūloma paprasta semantinio tinklo naršyklè, kuria galima naudotis net ir nesigiliant ị technines semantinio tinklo detales, taigi visi gali patogiai naršyti internete. 